\title{
Daniel A. Carrión en la Cripta de los Héroes
}

\author{
Daniel A. Carrion in the Crypt of Heroes
}

\section{Christian R. Miranda-Orrillo ${ }^{1}$}

1. Presidente de la Academia Peruana de Salud

Director general del Fondo Editorial Comunicacional CMP.

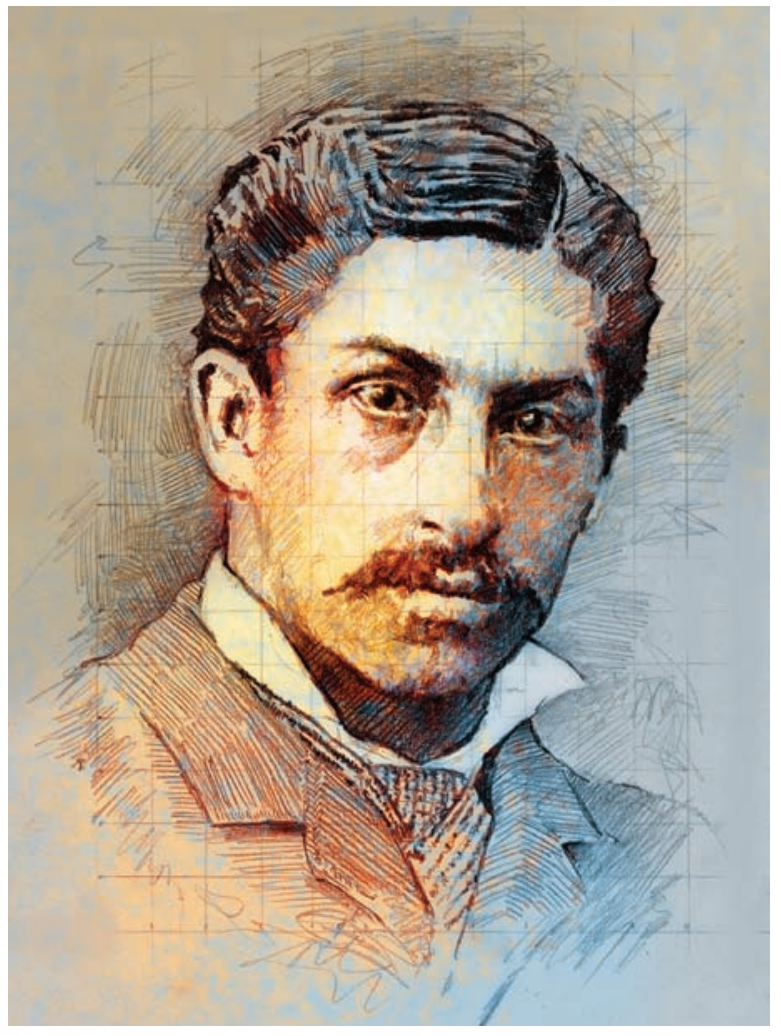

El 24 de marzo de 2015, el presidente emérito de la Asociación Médica Peruana "Daniel Alcides Carrión" y presidente honorario del Fondo Editorial Comunicacional del Colegio Médico del Perú, doctor Gustavo Delgado Matallana, con la aprobación del Ministerio de Defensa, presidió la ceremonia de colocación de una placa con el nombre de Daniel A. Carrión en uno de los muros de la Cripta de los Héroes, como un digno homenaje al hombre y héroe civil, logrando con ello perpetuar su valeroso heroísmo.
Con este trascendental acto se reivindica a Daniel A. Carrión (13 de agosto de 1857 - 05 de octubre de 1885), no solo como héroe civil o mártir de la medicina peruana, sino también por su heroico papel en la guerra contra Chile, llamada también "Guerra del Salitre" o “Guerra del Pacífico", en 1879.

Nos aunamos a los reconocimientos y homenajes a Daniel Alcides Carrión, ícono de la medicina peruana y ejemplo de quienes ejercemos este apostolado. En este número de Acta Médica Peruana presentamos un artículo escrito por el mismo gestor de esta iniciativa y tesonera e indesmayable labor, quien luego de veintiún años de arduas gestiones finalmente logró reconocimiento oficial por el Ministerio de Defensa, que otorgó a nuestro héroe el sitial que le corresponde junto a los demás héroes de nuestra nación.

El doctor Gustavo Delgado Matallana en el artículo “Daniel Alcides Carrión García en la Cripta de los Héroes de la Guerra de 1879" hace una reseña de dos sucesos históricos trascendentales que exaltan a Carrión como patriota y científico.

Como todos conocemos, nuestro país fue leal a los compromisos de defensa suscritos, por lo que el Perú protestó ante el gobierno chileno por la sorpresiva e injusta invasión y ocupación de los territorios bolivianos de Antofagasta, Mejillones y Caracol. A este requerimiento se sumaron, el 16 de marzo de 1879, los graduados y alumnos de las Facultades de la Universidad de San Marcos y de las Escuelas de Construcción y Minería, con un histórico pronunciamiento contra el alevoso asalto con menosprecio de la Ley Internacional y 
la civilización de nuestra época. La respuesta de Chile fue declarar la guerra al Perú, guerra para lo cual ellos se habían preparado con anterioridad, con el financiamiento y patrocinio inglés.

Los estudiantes de Medicina de San Fernando se reunieron nuevamente en abril y, en sesión solemne, acordaron por unanimidad -en histórico acto- ofrecer sus servicios profesionales al "Supremo Gobierno". Sin duda, Carrión participaba en el trajín de esta inquietud.

En diciembre de 1879, Daniel A. Carrión vive intensas emociones cuando acude, con el entusiasmo patriota del pueblo, a recibir y dar la bienvenida en la "Estación Desamparados", de Lima, al contingente procedente de Cerro de Pasco, o "Columna Pasco" integrado por connacionales, muchos de ellos amigos personales de Carrión, con quienes departe añoranzas de la tierra lejana.

La historia del héroe Daniel A. Carrión, como bien lo expresa el maestro Gustavo Delgado Matallana, se inicia en 1880. En el "Resumen Cronológico de los Hechos Históricos de la Guerra del Pacífico (1879-1881)", se indica en los escritos en el orden numérico $\mathrm{N}^{\circ} 65$, su participación en la convocatoria de reservas. Esta es una mención honrosa que se hace a Carrión, quien solo cursaba el primer año en la Facultad de Medicina de San Fernando.

También existe una composición fotográfica del Batallón "23 de diciembre", en recuerdo del golpe de estado de Nicolás de Piérola que lo llevó al poder, el año anterior; allí figura el retrato de Daniel A. Carrión como "abanderado", con el uniforme militar de subteniente temporal. Para ser abanderado se necesitaba tener un coraje a toda prueba, pues durante los combates era el blanco preferido del enemigo. Así, se demuestra que Carrión estuvo alistado, acuartelado y entrenado en el nuevo Ejército de Reserva del Perú y que desde un inicio demostró valentía coraje y determinación de entregar la vida por su Patria.

Los historiadores describen su participación en la Batalla de San Juan, en Lima, el 13 de enero de
1881, cuando apenas cursaba el segundo año en la Facultad de Medicina de San Fernando. Su misión patriótica y humanitaria la prodigó con riesgo de su vida en el fragor del combate. Participó como practicante de Medicina en las ambulancias de guerra, trasladando heridos, dándoles ayuda física y afectiva, colaborando en sus curaciones y, según lo dispuesto, recogía soldados inmolados para ayudar a sepultarlos en el mismo campo de combate.

Cuatro años más tarde, su pasión científica por desentrañar el enigma de la verruga peruana se evidenció en su mayor expresión, al inmolarse en su intento por hacer el bien a la humanidad. Carrión cursaba el sexto año en la Facultad de Medicina de San Fernando y ya tenía terminado su trabajo académico sobre la verruga peruana, para presentarlo como tesis y obtener el grado de bachiller en Medicina, con la conclusión que la verruga andina es una enfermedad infecciosa producida por un microorganismo patógeno y que es inoculable.

Con este objetivo, en un acto consciente, voluntario, científico y de mucho valor, Carrión llevó a la acción su propósito: el 27 de agosto, a petición suya, se le inoculó la sangre extraída de un paciente con verrugas, en el Hospital "Dos de Mayo". Carrión vivió 28 años. Falleció justamente cuando comenzaba a hacer planes para ir a Europa (a Francia), a mejorar la calidad de sus conocimientos académicos, y cuando reflexionaba sobre la importancia de la superación para poder ayudar al prójimo.

Hoy, nosotros somos conscientes de la gesta heroica de Carrión gracias al esfuerzo de muchos años del maestro Gustavo Delgado Matallana, digno heredero del legado histórico de ese gran hombre y recientemente reivindicado en la Cripta de los Héroes.

¡Que viva el nombre de Carrión por siempre en la Cripta de los Héroes nacionales! 